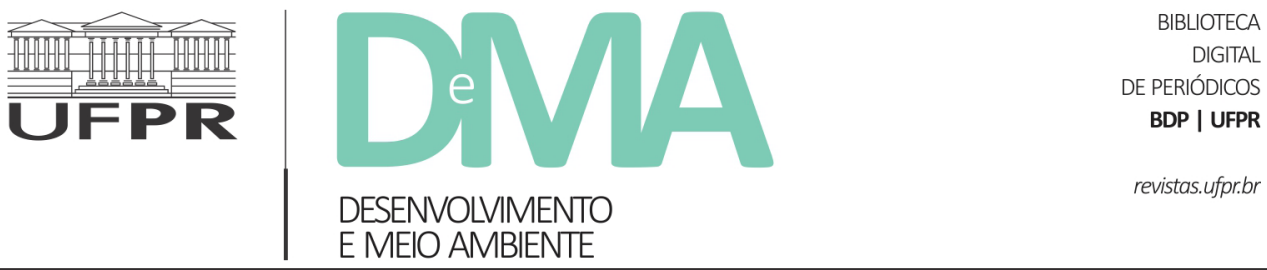

\title{
A cooperação multilateral climática e a promoção da agenda da transição energética no Brasil
}

\section{The multilateral climate cooperation and the promotion of the energy transition agenda in Brazil}

\author{
Alexandre César Cunha LEITE ${ }^{*}$, Elia Elisa Cia ALVES², Livia PICCHI ${ }^{1}$ \\ ${ }^{1}$ Universidade Estadual da Paraíba (UEPB), João Pessoa, PB, Brasil. \\ ${ }^{2}$ Universidade Federal da Paraíba (UFPB), João Pessoa, PB, Brasil. \\ *E-mail de contato: alexccleite@gmail.com
}

Artigo recebido em 22 de novembro de 2019, versão final aceita em 7 de julho de 2020, publicado em 25 de novembro de 2020.

RESUMO: Cooperação multilateral, regime internacional, governança global, segurança energética e meio-ambiente são temas intrinsicamente relacionados, embora nem sempre as conexões sejam evidentes. Partimos do questionamento de como a agenda internacional climática se desdobra para políticas domésticas de mitigação no setor de energia em um país em desenvolvimento. Para lidar com essa questão, identificamos os princípios estabelecidos internacionalmente no que tange à temática das energias renováveis, com a finalidade de minimizar os impactos ambientais ocasionados pelos Gases de Efeito Estufa. Na sequência, apresentamos uma análise sobre a evolução da agenda multilateral climática internacional com foco para o setor energético e pontuamos seus desdobramentos na adoção de energias renováveis no Brasil. A partir de uma revisão bibliográfica da questão climática pela perspectiva racional-institucionalista, passando pelas abordagens de regime internacional, governança climática, governança policêntrica e uma análise empírica de mudanças político-regulatórias no Brasil, buscamos identificar os diferentes vetores que traduzem diretrizes internacionais em políticas domésticas. Discute-se a cooperação como estratégia para lidar com questões que se relacionam à segurança energética dos países e, concomitantemente, com a perspectiva ambiental.

Palavras-chave: energias renováveis; regimes internacionais; governança policêntrica ambiental; cooperação internacional.

ABSTRACT: Multilateral cooperation, international regime, global governance, energy security and the environment are intrinsically related issues, although the connections are not always evident. We started with the question of how the international climate agenda unfolds for domestic mitigation policies in the energy sector in 
a developing country. In order to deal with this issue, we have identified the principles internationally established with regard to the theme of renewable energies, in order to minimize the environmental impacts caused by Greenhouse Gases. We then present an analysis of the evolution of the international multilateral climate agenda with a focus on the energy sector and point out its developments in the adoption of renewable energies in Brazil. From a bibliographic review of the climate issue from a rational-institutionalist perspective, through the approaches of international regime, climate governance and polycentric governance followed by an empirical analysis of political and regulatory changes in Brazil, we seek to identify the different vectors that translate international guidelines into domestic policies. Cooperation is discussed as a strategy to deal with issues related to the countries' energy security and, at the same time, with the environmental perspective.

Keywords: renewable energy; international regimes; polycentric environmental governance; international cooperation.

\section{Introdução}

Como superar o desafio da transição energética? O desenvolvimento e o aprimoramento das novas tecnologias, que modificaram o modo de vida da população mundial, acarretaram em um aumento na demanda por energia. Do lado da oferta, já nos anos 1970, diante das duas crises de oferta de petróleo $(1973,1979)$, a preocupação com a garantia de suprimentos energéticos fez com que os países adotassem medidas e estratégias cujo objetivo era garantir o abastecimento de energia (segurança energética), diminuindo a dependência dos países membros ao petróleo e seus derivados (Alves et al., 2019). Naquela época, os países passaram a se articular visando a fomentar a cooperação técnica na busca por fontes alternativas ou otimização das existentes, através de, entre outras iniciativas, a criação da International Energy Agency (IEA) em 1974, no bojo da Organização de Cooperação e de Desenvolvimento Econômico (OCDE) (Yergin, 2008).

Paralelamente às questões relacionadas à oferta de energia e à segurança energética, multi- plicaram-se os esforços dos países em responder à comunidade internacional que passou, principalmente, ao longo dos anos 1990, a buscar soluções de mitigação ${ }^{1}$ dos efeitos negativos das mudanças climáticas através da minimização de emissões de Gases de Efeito Estufa (GEE) (IPCC, 2014). A geração e o uso de energia são as principais fontes globais de emissão de GEEs, com tendência média de crescimento de $23.366 \mathrm{em} 1990$ para $36.013 \mathrm{em}$ 2016, ainda que em desaceleração (principalmente entre 2013 e 2016). Diante desse quadro, o desenvolvimento de fontes renováveis de energia, visando a um menor impacto ambiental, e de programas de eficiência energética passaram a ser uma preocupação mundial (de Souza et al., 2011).

No que concerne aos conceitos supracitados, utilizamos a classificação da Agência Internacional de Energia Renovável (IRENA, 2009), que define 'energia renovável' como derivada de processos naturais que são reabastecidos a uma taxa mais elevada do que são consumidos. As energias solar, eólica, geotérmica, hidrelétrica, bioenergia e oceânica são, assim, fontes de energia renovável. Essas fontes são empregadas na geração de eletricidade,

${ }^{1}$ Mitigação é "o esforço para controlar as fontes humanas de mudança climática e seus impactos cumulativos, notadamente a emissão de GEE e
outros poluentes, como partículas de carbono preto, que também afetam o balanço energético do planeta” (IPCC, 2014, p. 114, tradução livre). 
aquecimento e no setor de transportes. Por vezes, o termo 'energia renovável' exclui grandes centrais hidrelétricas, por provocarem outros problemas ambientais. No Brasil, os termos 'energia limpa' ou 'energia alternativa' são comumente utilizados para tal sentido. Ao longo deste texto, o termo 'energia renovável' dialoga com a literatura internacional que discute o tema e descarta a energia nuclear (englobada pelo termo 'energia limpa'). Utilizamos o etanol como exemplo, apesar de ser considerada pela literatura internacional um tipo de fonte renovável, não necessariamente reproduz o modelo social ou ambientalmente sustentável, como é o caso das monoculturas do etanol (Lakoff, 2014; Harjanne \& Korhonen, 2019). Entretanto, como a produção de etanol também é incentivada no escopo da agenda climática internacional, pela lógica da menor emissão de GEE vis-à-vis à queima de combustíveis fósseis, essa fonte foi mantida nessa análise.

Os programas de eficiência energética são entendidos como um conjunto de práticas e políticas que reduzem o custo de energia e/ou aumentam seu suprimento sem aumentar a quantidade de energia gerada; envolvendo planejamento integrado e simplificado de recursos. Existem dois focos na promoção de projetos de eficiência: no lado da oferta ou no consumo final (demanda). Do lado da oferta, é a eficiência na geração, transmissão e distribuição, por meio de práticas e da inserção de tecnologias que estimulam a eficiência em toda a cadeia energética. Do lado da demanda, corresponde a medidas que culminam na redução de energia necessária para atender às demandas da sociedade, por meio de tec- nologias e práticas destinadas a garantir a redução do consumo final. Isso pode ser alcançado pelo uso de dispositivos de controle do consumidor ou pelo melhor uso da energia, rotulagem de aparelhos elétricos ou programas socioeducativos, resultando em um uso mais consciente e racional da energia elétrica (Ribeiro, 2005).

Adicionalmente à questão ambiental, esse nicho de mercado se tornou um importante vetor de investimentos em pesquisas e alvo de políticas públicas, visando à viabilidade econômica de sua comercialização, após um programa de financiamento público, como mostra Podcameni (2014) para o caso do setor eólico.

Assim, para além da perspectiva da segurança energética como fator estratégico para a soberania nacional, especificamente do ponto de vista econômico e militar (Salomão \& Silva, 2007; Siqueira, 2011), passou-se a considerar, também, a política energética como um eixo potencial para o desenvolvimento sustentável ${ }^{2}$ (IPCC, 2011). Tal importância foi reforçada nas metas internacionais, haja vista menção atribuída nos Objetivos do Desenvolvimento Sustentável (ODS) da Agenda 2030 da ONU às energias renováveis (ODS 7), às mudanças climáticas (ODS 13) e parcerias e regimes para a governança dos ODS (ODS 17).

Nesse bojo, o termo segurança energética passou a ter um sentido mais abrangente, para além da garantia de abastecimento, englobando comércio, inovação, mudança climática, acessibilidade econômica e a dimensão ambiental (Sovacool et al., 2013). Observando-se, portanto, não apenas o lado da oferta de energia, mas também o lado da

\footnotetext{
${ }^{2}$ Por desenvolvimento sustentável, convencionou-se chamar aquele desenvolvimento que satisfaz as necessidades presentes, sem comprometer a capacidade das gerações futuras de suprir suas próprias necessidades. Tal modelo de desenvolvimento possui três componentes principais, os quais: desenvolvimento econômico, equidade social e a proteção ambiental (ONU, 2020).
} 
demanda, com questões dos serviços e políticas de energia, juntamente com o desenvolvimento de tecnologias e infraestrutura.

Nesse sentido, faz-se necessário compreender como as políticas no setor de energia no âmbito doméstico são influenciadas por acordos e esforços de cooperação estabelecidos internacionalmente no âmbito das negociações sobre mudanças climáticas. Através de uma análise qualitativa que envolve uma revisão da literatura racional-institucional, sobre a governança internacional do clima, e de uma pesquisa empírica do caso do Brasil, com análise de documentos, regulação e relatórios oficiais, buscamos apontar algumas lacunas na conexão entre vetores internacionais e a disseminação da energia renovável no Brasil, focando a formulação e implementação de políticas públicas domésticas.

A pesquisa se justifica por dois motivos. Primeiramente, pelo ponto de vista temático, ao contribuir na agenda de pesquisas que ligam o plano internacional ao doméstico na arena da política energética, estabelecendo como foco as renováveis. A energia renovável é, cada vez mais, considerada pelos decisores políticos como uma forma fundamental de energia para mitigar os efeitos das mudanças climáticas, melhorar a segurança energética, reduzir a poluição do ar local e gerar emprego (Mitchell et al., 2011). Segundo, do ponto de vista teórico, uma agenda crescente de pesquisas aponta para a exploração de caminhos que superem os impasses da implantação de diretrizes internacionais na esfera da energia, sugerindo que a governança policêntrica ambiental parece mais adequada para abarcar os esforços de formulação e implementação de políticas públicas em nível nacional, envolvendo múltiplos atores e instituições diante da complexidade da questão (Jordan \& Huitema, 2014).
O Brasil torna-se importante como caso a ser analisado por dois motivos: (i) além de ter desempenhado um papel de destaque nas negociações do clima no plano internacional, também promoveu, domesticamente, um processo sui generis de condução de formulação de política externa com ampla participação da sociedade civil antes de estabelecer seu comprometimento internacional o que pode ter despertado uma difusão de princípios internacionais para atores domésticos (Faria, 2017) e (ii), apesar de ter parte relevante de emissões de GEE oriundas do desmatamento, o setor de energia tem crescente participação nas emissões brasileiras, conforme será indicado na seção 4, e o país é o maior emissor na América Latina (CAIT, 2020).

Do ponto de vista metodológico, foi realizada uma revisão narrativa da literatura, dos documentos oficiais e policy papers de instituições internacionais com o intuito de associar os regimes internacionais e a governança global às tentativas locais de estabelecimentos de acordos e de políticas ativas de mitigação dos impactos ambientais via adoção de fontes de energia renováveis. Estas mesmas fontes documentais, associadas a informes oriundos de mídia especializada, serviram para acompanharmos a evolução da promoção das energias renováveis.

Além dessa introdução, o artigo está organizado em mais quatro seções. A seção 2 faz uma revisão dos principais estudos na linha do meio-ambiente sob a ótica da teoria de regimes internacionais e da governança global. A seção 3 traça um painel histórico da formação de uma agenda internacional no sentido de impulsionar a produção energética, a partir de fontes renováveis, envolvendo a promoção de publicações científicas, eventos multilaterais, estabelecimento de acordos, iniciativas e instituições. $\mathrm{Na}$ seção 4, a atenção se volta para os desdobra- 
mentos dos esforços internacionais relacionados ao tema da energia renovável, com um olhar específico para o caso do Brasil. A última seção pontua as considerações finais da discussão.

\section{Da teoria dos regimes internacionais à governança policêntrica global: os olhares sobre o meio-ambiente na perspectiva racional-institucionalista}

As questões ambientais ganharam uma projeção no cenário internacional já nos anos 1960, com a publicação de Rachel Carson (1962) e nos 1970s, com publicações importantes Limits to Growth (Meadows et al., 1972) e Blueprint for Survival (Goldsmith et al., 1972), além da Conferência das Nações Unidas (ONU) de Estocolmo, de 1972. O primeiro fórum intergovernamental ambiental foi importante para despertar a temática ambiental na agenda internacional.

Como será discutido na seção 3 , nos anos 1990, o reflexo das novas configurações do cenário internacional possibilitou um abrangente debate em torno da concepção de regimes internacionais, os temas referentes às negociações e aos processos de formação de agenda e implementação permaneceram centrais nas análises (Young, 1989; 1999; Mitchell et al., 1994). Com o fim da Guerra Fria, novos temas passaram a ocupar lugar de destaque na agenda internacional, como meio ambiente e direitos humanos (Sato, 2000).

Nesse campo, as questões ambientais globais são analisadas a partir das lógicas da Ação Coletiva
(Olson, 1965) e da Tragédia dos Comuns (Hardin, 1968), com estudos sobre os regimes internacionais, fundamentados nas obras de Ruggie (1982), Krasner (1983) e Keohane (1984) ${ }^{3}$. Nesse bojo, o aumento de transparência e a diminuição dos custos de transação fazem com que as instituições afetem a disposição dos Estados em cooperar, a partir da identificação de interesses comuns e da redução de incertezas (Gilligan, 2006).

Os estudos sobre o ambientalismo ganharam grande relevância na década de 1990, com o aumento das investigações sobre os vínculos entre a economia internacional e a dimensão ambiental sob a perspectiva da cooperação e seus dilemas, subsidiado em teorias de cunho liberal-institucionalista. Porém, para além da ampliação temática, foi crescente o reconhecimento da importância dos atores não estatais, das formas não militares do poder e da interdependência (Baylis, 2020). Na visão de Veiga \& Zacareli (2015), a ideia de regime internacional dos anos 1980, ao enfatizar a coordenação de ações em parceria com o terceiro setor e as empresas privadas, foi ampliada para o conceito de governança global.

Nesse bojo, Ostrom (1990) desenvolveu uma importante crítica à ideia da Tragédia dos Comuns ao desvendar que, no âmbito local, grupos conseguiam se articular na governança de recursos de uso comum, evitando seu esgotamento. Buscava-se compreender se, para além das regras e princípios, a estrutura de governança envolvendo fatores tais quais a atribuição de papeis, responsabilidades e o monitoramento de recursos baseados na comunidade poderiam impactar positivamente a preservação

\footnotetext{
${ }^{3}$ Krasner (1983, p. 2) define regime como "um conjunto de princípios implícitos ou explícitos, normas, regras e procedimentos de decisão em torno dos quais as expectativas dos atores convergem em uma determinada área".
} 
do meio ambiente. Um conjunto de estudos se desenvolveram a partir dessa perspectiva, baseando-se em grupos de trabalhos coordenados pelos pesquisadores Vincent e Elinor Oström (Ostrom, 2009; McGinnis, 2011).

Young (1997) lança uma obra abrangente nesse sentido e Keck \& Sikkink (1998) marcam o período com sua obra sobre a atuação de ato- res não governamentais. Essa linha tomou ainda mais fôlego com o lançamento no ano de 2000 do Journal of Global Environmental Politics (GEP) e o fortalecimento do campo da Política Ambiental Global (Clapp \& Helleiner, 2012; Chasek, 2018), com destaques de diferentes abordagens teórico e metodológicas, a partir de estudos consolidados na Tabela 1.

TABELA 1 - Contribuições empíricas na linha da Governança Ambiental Global.

\begin{tabular}{ll}
\hline $\begin{array}{c}\text { Framework Teórico-ana- } \\
\text { lítico }\end{array}$ & \multicolumn{1}{c}{ Evoluções Conceituais } \\
\hline & $\begin{array}{l}\text { (i) Regimes como conjunto de princípios (implícitos ou } \\
\text { explícitos), normas, regras e procedimentos de decisão em } \\
\text { torno dos quais as expectativas dos atores convergem em uma } \\
\text { determinada área }\end{array}$ \\
& (ii) Princípios de coordenação baseados nas ideias de Ação \\
Regime Internacional & Coletiva (Olson, 1965) e da Tragédia dos Comuns (Hardin, \\
&
\end{tabular}
Ruggie (1982) — regimes internacionais
Krasner (1983) — regimes internacionais
Keohane (1984) — regimes internacionais
Mitchell et al. (1994) — regime marinho
Young $(1989 ; 1999)$ - cooperação e eficácia de
regimes internacionais

Governança Global Ambiental
Novas formas de cooperação para além do Estado (atores não estatais), como (i) parcerias e iniciativas do setor privado, (ii) organizações da sociedade civil e (iii) redes de compartilhamento.

\author{
Ostrom (1990) — governança comuns \\ Young (1997) — multitemático \\ Falkner (2003) - setor privado \\ Haas (2005) - comunidades epistêmicas \\ Dauvergne (2005) - multitemático \\ Biermann (2006) — atores não estatais \\ Ivanova (2007) - Agências da ONU \\ Bauer (2009) - Secretariados \\ Falkner (2013) — multitemático
}

Ostrom (2009; 2010; 2016)

Liu (2010)

Cole (2015) — vantagens da governança policêntrica

Jordan et al. (2015) — dificuldade de monitoramento e eficácia

Dorsch \& Flacsland (2017) — necessidade de caracterização e sistematização

FONTE: Elaboração própria. 
Na tentativa de identificar os atores relevantes da governança ambiental global, Biermann (2006) destaca: a) o aumento da participação de atores não estatais (redes de conhecimento, ambientalistas, corporações multinacionais, organizações intergovernamentais); b) novas formas de cooperação para além das negociações de acordos internacionais (parcerias e redes de compartilhamento) e c) policy-making por meios verticais (governança multinível) e horizontais (governança multipolar).

Nessa toada, Falkner (2003) traz importantes contribuições sobre o papel do setor privado e Haas (2005) em relação às redes de conhecimento, sobre o papel do Intergovernmental Pannel on Climate Change (IPCC) na agenda climática internacional. Ivanova (2007) discute o papel do Programa das Nações Unidas para o Meio Ambiente (UNEP, em inglês) e Bauer (2009) mostra que o Secretariado da Convenção sobre Desertificação foi responsável pela mudança de percepção de que o problema era localizado, afirmando o poder do discurso como elemento determinante na saliência internacional da questão. Dauvergne (2005) e Falkner (2013) são alguns exemplos de obras que reúnem diversos trabalhos nessa linha.

Já a perspectiva da governança policêntrica difere-se em compreender, para além da esfera estatal e da ação de atores não estatais, a falta de coordenação global em torno do cumprimento das metas climáticas, incentivou inúmeras iniciativas multilaterais, minilaterais, subnacionais e não estatais, de maneira descoordenada, no sentido de atingir essas metas. Ostrom (2009; 2010; 2016) propõe considerar as ações em vários níveis de análise, com a supervisão ativa das partes interessadas locais, regionais e nacionais. A abordagem reconhece os esforços para reduzir as emissões individuais e ter responsabilidade em unidades de governança de pequena a média escala ligadas por redes de informação e monitorando em todos os níveis. Liu (2010) destaca que essa perspectiva se mostra promissora uma vez que a coordenação e a supervisão em níveis mais locais dispõem de uma rede mais ampla e potencialmente mais resistente na luta contra as mudanças climáticas. Dentre as oportunidades, Cole (2015) destaca mais possibilidades de experimentação e aprendizado de políticas, ampliando canais de comunicação e interação, formal e informal, bilateral e multilateral.

Essa abordagem reflete uma tendência da política internacional que destaca o maior espaço de interlocução de atores governamentais subnacionais, com a percepção de que a solução dos inúmeros problemas globais, como os relacionados a meio ambiente, direitos humanos, segurança, entre outros, passa pela esfera local (Liu, 2010; Cole, 2015). Ao mesmo tempo, esses atores nem sempre dispõem de recursos técnicos e financeiros para acessar tais questões. Por esse motivo, a maior projeção internacional na busca por parcerias e entidades financiadoras também cresce. Fato é que cidades e estados têm buscado se articular para galgar voz no sistema internacional.

Do lado dos desafios, Dorsch \& Flachsland (2017), em um tom de crítica, observam que a terminologia policêntrica oferece uma compreensão descritiva que demanda caracterizações específicas para que seja um desenho eficiente no sentido de compor o regime de governança climática. Através de uma revisão dos trabalhos que abordam a partir desse viés, estruturam quatro aspectos importantes da governança policêntrica: (i) ênfase na auto-organização (ii) reconhecimento das condições específicas do local, (iii) facilitação da experimen- 
tação e aprendizado e (iv) construção de confiança. Jordan et al. (2015) também destacam que, apesar do otimismo sobre iniciativas relevantes fora do regime internacional, é difícil o monitoramento de sua eficácia.

A partir desse enquadramento das abordagens teórico-conceituais pela ótica racional-institucionalista, passamos para a evolução histórico-institucional da construção e evolução do regime internacional de mudanças climáticas (RIMC) ao modelo de governança policêntrica, com um olhar para a promoção de políticas de mitigação de GEE, focando o setor de energia.

\section{A transição energética do regime internacional à governança policêntrica das mudanças climáticas: a construção $e$ evolução histórico-institucional}

Analisando a evolução da promoção das energias renováveis no contexto da agenda climática internacional em relação aos esforços de transição energética nos países, identificamos ao menos cinco vetores de cooperação multilateral que, de maneira policêntrica, acabaram influenciando as trajetórias regulatórias e tecnológicas no sentido da promoção das energias renováveis: (i) conferências internacionais (participação e/ou sediando esses eventos); (ii) criação de organizações multilaterais e redes público-privadas; (iii) acordos internacionais; (iv) fatos históricos que promoveram mudanças estruturais relacionadas ao setor energético e (v) publicações oferecendo amparo técnico e disseminando ideias conectadas ao tema. Apresentamos tais fenômenos, de maneira mais sucinta, na Tabela 2.
A Conferência da ONU sobre Novas Fontes de Energia realizada em Roma, em 1961, é considerada o primeiro grande encontro internacional sobre energias renováveis. Seu objetivo foi explorar a aplicação prática de fontes energéticas que, à época, eram apenas implementadas em baixa escala: a energia solar, eólica e a geotérmica. Já na Conferência de Estocolmo, em 1972, o tema energia obteve pouca atenção. Teixeira de Barros (2017) mostra que, ao longo das apresentações e discursos, apenas duas menções foram feitas nos discursos referentes ao tema de energias alternativas. Nos acordos finais, não houve menção à temática energética e o evento concentrou-se em discutir o aquecimento global, ainda um tema circunscrito apenas ao contexto acadêmico na ocasião (Rowlands, 2012). Ainda assim, Viola (2002) sugere que esse encontro multilateral se configura como o primeiro evento de grande envergadura com relação as questões ambientais de uma perspectiva abrangente que marcou a temática ambiental no cenário internacional.

Em 1981, após os choques do petróleo, a ONU promoveu uma conferência específica para a temática de fontes renováveis de energia, em Nairóbi. Embora tenha sido um evento de abrangência global, Rowlands (2012) sugere que o discurso estava voltado para atender a necessidades dos países em desenvolvimento, os quais sofriam de graves desequilíbrios em seus balanços de pagamentos, por conta dos drásticos aumentos do preço do petróleo.

Conforme Aguiar et al. (2015), os anos 1980 consolidaram a temática climática no debate ambiental. O acidente em Chernobyl, em 1986, na União Soviética, fomentou a oposição à energia nuclear pela opinião pública internacional e as organizações da indústria de renováveis começaram a se coordenar. Nesse ponto, países como Alemanha 
TABELA 2 - Do regime internacional à governança policêntrica do clima, com foco para o setor energético.

\begin{tabular}{|c|c|c|c|c|}
\hline Ano & Conferências Internacionais & $\begin{array}{c}\text { Organizações Multilaterais/Ini- } \\
\text { ciativas Público-Privadas/ Acordos } \\
\text { Internacionais }\end{array}$ & Fatos históricos & Publicações \\
\hline
\end{tabular}

Conferência da ONU sobre

Novas Fontes de Energia

(Roma)

Conferência de ONU para

o Meio-Ambiente Humano

(Estocolmo)

1973

1974

1981

1986

1988

1997 o Meio-Ambiente (Rio de Janeiro)

Conferência da ONU para

Energias Renováveis (Nairóbi)
Programa das Nações Unidas para o

Meio Ambiente (PNUMA)

Primeiro Choque do

Petróleo

International Energy Agency (IEA)

Segundo Choque do Petróleo

Acidente em Chernobyl

Painel Intergovernamental sobre Mudanças Climáticas (IPCC)

Comissão das Nações Unidas sobre Desenvolvimento Sustentável (CDS); Agenda21; UNFCCC

Global Environmental Facility (GEF)

Assinatura Protocolo de Kyoto
Silent Spring (Carson, 1962)

Limits to Growth (Meadows et al., 1972) e Blueprint for Survival (Goldsmith et al.,1972)
Our Common Future (Brundtland, 1987)

Conferência da ONU do De-

2002 senvolvimento Sustentável

(Johanesburgo)

Agência Internacional de Energias Renováveis (IRENA)
Crise Financeira Internacional;

Queda preço petróleo

Queda preço petróleo 

ONU
Crise Euro; Queda preço

petróleo

Crise Euro

Global Green New Deal; Emenda de Doha

GEO-5

The Future We Want (FWW) (ONU, 2012)
Fórum de Alto Nível Político sobre Desenvolvimento Sustentável substituindo o CDS

Lançamento da Agenda 2030 (ODS da ONU); Acordo de Paris (2015)

*GEO: Panorama Ambiental Global.

FONTE: Elaboração própria.

e a Dinamarca estruturavam um aparato de financiamento e subsídios de tecnologias renováveis nesses países, fundamental para o desenvolvimento do setor de renováveis (Camillo, 2013). Das publicações, o relatório Brundtland (1987), "Our Common Future", consolidou ideia de desenvolvimento sustentável, vinte anos após a primeira conferência internacional sobre meio ambiente, na Conferência da ONU para o Meio Ambiente e o Desenvolvimento em 1992, conhecida como Eco92, realizada no Rio de Janeiro, Brasil. Na proposta, os países costuraram mecanismos de cooperação e de ações multilaterais, com a consolidação de planos de ação no documento Agenda 21, com o objetivo de promover o desenvolvimento econômico, de maneira sustentável, e conter as emissões de GEE.

Os anos 1990 representam, portanto, a consolidação do tema das mudanças climáticas na agenda internacional. Quanto à temática da energia de uma maneira geral, note-se que não foi tema principal em nenhum capítulo da Agenda 21, recebendo apenas algumas considerações modestas ao longo do documento, com referências à questão do suprimento energético aos países em desenvolvimento (Rowlands, 2012). Do ponto de vista da agenda climática, o ponto mais relevante na Conferência foi o estabelecimento da Convenção Quadro de Mudanças Climáticas da ONU (UNFCCC, em inglês), aberta à assinatura dos Estados na ocasião, com o objetivo de monitorar e prever mecanismos multilaterais visando controlar emissões de GEE.

O documento entrou em vigor em 1994, sendo ratificada por 195 países. Nesse contexto, a questão energética ganhou projeção, por constituir, globalmente, a maior fonte de emissão de GEE (ver Figura 1). 


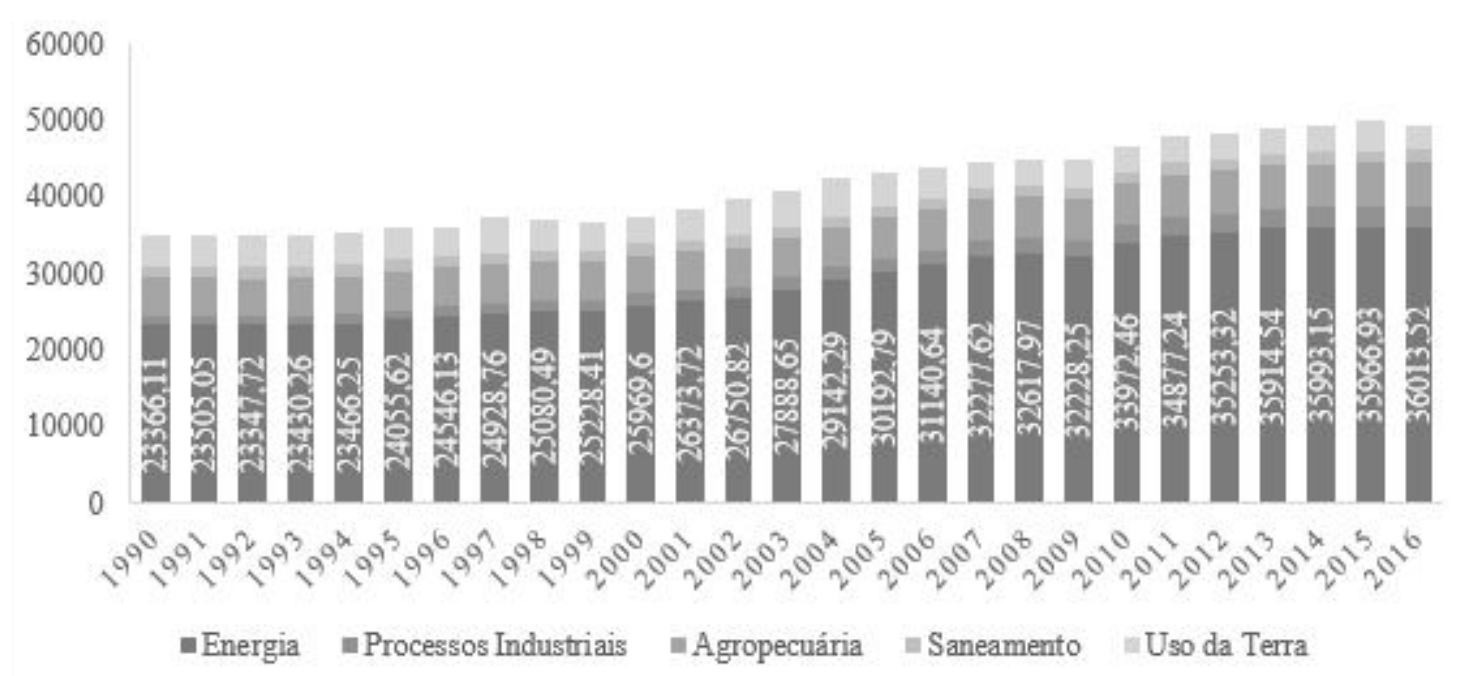

FIGURA 1 - Emissões líquidas de gases estufa no mundo, por setor, de 1990 a 2016. (MtCO2eq). Destaque para o setor de energia (com os valores descritos) (MtCO2eq).

FONTE: Elaboração própria com base em CAIT (2020).

A UNFCCC (1992) ressalta em seu preâmbulo que os países signatários reconhecem a necessidade de revisar produção energética com medidas relativas ao setor de energia, com a promoção da eficiência energética e o uso de novas tecnologias. No artigo $4^{\circ}$, os países comprometem-se a promover e cooperar no desenvolvimento, aplicação e difusão de práticas e processos e na transferência de tecnologia, que controlem, reduzam ou evitem emissões antrópicas de GEE em diversos setores, com destaque para o setor de energia.

A despeito de a UNFCCC não estabelecer metas, constituiu um passo diplomático para futuras negociações nesse sentido. Com sua entrada em vigor, iniciou-se o processo de negociações em uma estrutura de Conferências das Partes
$(\mathrm{COPs})^{4}$ promovidas anualmente, funcionando como instância de regulamentação e ajustamento do RIMC, com possibilidade de adotar protocolos e instrumentos legais de enfrentamento da questão climática (Siqueira, 2011). Com isso, também se construiu um foro de compartilhamento de percepções e iniciativas, permeando governos no sentido de uma mudança de paradigma quando se trata de crescimento econômico, aliado à preservação do meio ambiente e à exploração sustentada de seus mais variados recursos, incluindo-se os recursos energéticos (Viola \& Gonçalves, 2019).

A Eco92 foi importante, também, para a criação de dois órgãos fundamentais para a emergência do tema energia na agenda internacional. O primeiro é a Comissão das Nações Unidas sobre Desenvol-

\footnotetext{
${ }^{4}$ A primeira COP foi realizada em 1995, em Berlim, e até dezembro de 2019 foram realizadas 25 COPs.
} 
vimento Sustentável ${ }^{5}$ (CSD, em inglês), um órgão ligado ao Conselho Econômico e Social da ONU (ECOSOC, em inglês), encarregado de supervisionar os resultados da Rio92. O segundo é o Global Environmental Facility (GEF, em inglês), ou Fundo Mundial do Ambiente, criado para prover recursos e fundos concessionais, a fim de cobrir projetos que beneficiem o meio ambiente global.

O GEF tornou-se o instrumento oficial de financiamento das agências que têm a função de desenhar, desenvolver e implementar os projetos amparados pelas cinco convenções internacionais sobre o meio ambiente negociadas na Eco92 ${ }^{6}$. Os projetos relacionados à energia são operacionalizados por dezoito agências e programas, como o UNEP e o UNDP. Até 2020, o fundo havia financiado cerca de 326 projetos exclusivamente relacionados à temática de energia renovável ou eficiência energética (de um total de cerca de 1.951 relacionados ao tema de Mudanças Climáticas), contabilizando um total de mais de US\$ 1,6 bilhão de subvenções, conforme a Tabela 3.
Vale notar que, conforme Veiga \& Zacareli (2015), o sentido para qual sinalizavam as negociações no bojo da Rio-92 já indicava importantes mudanças na questão da governança ambiental que se tornaram mais evidentes, principalmente, pós-2002. A Agenda 21, por exemplo, defendia a complementaridade de políticas governamentais com ações e programas do setor privado e de organizações não governamentais (ONGs) para a superação dos desafios ambientais, dentre os quais, as mudanças climáticas.

Passaram-se nove anos após a Rio-92 para que a comunidade internacional se voltasse exclusivamente à questão energética, em 2001, com a promoção de um encontro na $9^{\circ}$ sessão do CSD, em Nova Iorque. Deste evento em diante, os países desenvolvidos também passaram a ser inseridos nos documentos oficiais sobre a importância da disseminação das tecnologias de energia renovável. Já em 2002, no contexto da Conferência Mundial do Desenvolvimento Sustentável, realizada em Johanesburgo, a energia apareceu como uma das

TABELA 3 - Número e valor de projetos relacionados à eficiência energética e energia renovável.

\begin{tabular}{lccc}
\hline \multicolumn{1}{c}{ Contagem de Projetos } & Valor do Subsídio (US\$) & Co-financiamento (US\$) \\
\hline Eficiência energética & 164 & $776.820 .204,00$ & $9.731 .964 .643,00$ \\
Energia renovável & 162 & $868.153 .701,00$ & $8.399 .587 .619,00$ \\
Mudanças Climáticas & 1767 & $7.569 .473 .732,00$ & $60.838 .686 .800,00$ \\
Total de Projetos & 5058 & $19.068 .741 .272,00$ & $121.013 .763 .485,00$ \\
\hline
\end{tabular}

FONTE: Elaboração própria com base em GEF (2020). A análise foi feita baseando-se nas informações disponíveis no Banco de Dados do Órgão. Foram contabilizados todos os projetos que continham as palavras "energy efficiency", "renewable energy", ou "solar", ou "wind" ou "geothermal". Foram eliminados projetos duplicados (que apareceram em duas buscas, por exemplo).

\footnotetext{
${ }^{5}$ Em 2013, o CSD foi substituído pelo Fórum de Alto Nível Político sobre Desenvolvimento Sustentável, que se reúne no âmbito da Assembleia Geral a cada quatro anos, no ECOSOC em outros anos.

${ }^{6}$ São elas: Convenção de Minamata sobre Mercúrio, Convenção de Estocolmo sobre Poluentes Orgânicos Persistentes (POPs), a Convenção da ONU de Diversidade Biológica, a Convenção da ONU para Combate de Desertificação e a Convenção-Quadro da ONU para Mudanças Climáticas.
} 
cinco prioridades do evento, definido pelo anacrônico WEHAB, em inglês, water and sanitation (água e saneamento), energy (energia), health (saúde), agriculture (agricultura) e bio-diversity (biodiversidade). Nesse sentido, debates passaram a emergir em torno do estabelecimento de metas e prazos para a adoção de energia renovável, da redução de subsídios a energias fósseis e dos termos de transferência de tecnologias de países desenvolvidos para países em desenvolvimento. Assim, o Plano de Ação resultante do evento culminou em maior atenção ao tema, embora não tenha estabelecido princípios efetivos para toda a comunidade internacional, diante de profundas divergências nas negociações entre os países.

Neste ínterim, o ano de 1997 foi um marco, com a negociação do Protocolo de Kyoto, estabelecendo as metas, diretrizes e princípios do RIMC, como uma extensão da UNFCCC (Viola, 2002). O acordo, que entrou em vigor em 2005, propunha um calendário pelo qual os países membros do Anexo $\mathrm{I}^{7}$ teriam a obrigação de reduzir a emissão de GEE em pelo menos 5,2\% em relação aos níveis de 1990 no período de 2008 até 2012. Seu conteúdo representou um esforço em estabelecer metas, através da cooperação, visando ao desenvolvimento de tecnologias de energia renovável e de eficiência energética (UNFCCC, 1992, art. $2^{\circ}$ ).

Dessa forma, para atingir a redução estabelecida, era preciso promover a eficiência em toda cadeia energética, bem como expandir novas formas de produção energética, a partir de fontes renováveis, em meio a debates tensionados entre países desenvolvidos, com maior capacidade técnico-financeira de financiamento de novos projetos, versus países em desenvolvimento, ainda em processo de industrialização. Uma saída para esse impasse foi o estabelecimento do Mecanismo de Desenvolvimento Limpo (CDM, em inglês). Os países do Anexo I podem gerar ou comprar reduções certificadas de emissão de projetos desenvolvidos em países fora do Anexo I, com a contrapartida de acesso a recursos financeiros e tecnologias limpas, o que envolveu amplamente projetos de eficiência energética e energia renovável (Almeida et al., 2017). Entre 2003 e 2020, mais de 13.000 projetos já foram financiados dentro desse framework no mundo todo, a maior parte, em torno de $87 \%$, no setor de energia (CDM, 2020).

Em Bali (2007), a COP13 iniciou preparativos para um novo acordo climático que seria concretizado na COP15, em Copenhague (2009). Na ocasião, foi aprovada a implementação efetiva do Fundo de Adaptação, para que os países mais vulneráveis à mudança do clima pudessem enfrentar seus impactos, e sugerissem ainda as Ações de Mitigação Nacionalmente Adequadas (NAMAS), uma proposta de modelo para os países em desenvolvimento. No entanto, nenhuma das reuniões logrou em alcançar um acordo final. Um segundo período de compromissos foi acordado em 2012, conhecido como a Emenda de Doha que, até 2020, não havia entrado em vigor ${ }^{8}$.

\footnotetext{
${ }^{7}$ Países Anexo I, em 1992, eram “Alemanha, Austrália, Áustria, Bielo-Rússia, Bélgica, Bulgária, Canadá, Comunidade Econômica Europeia, Dinamarca, Eslováquia, Espanha, Estados Unidos, Estônia, Rússia, Finlândia, França, Grécia, Hungria, Irlanda, Islândia, Itália, Japão, Letônia, Lituânia, Luxemburgo, Mônaco, Noruega, Nova Zelândia, Países Baixos, Polônia, Portugal, Reino Unido, Romênia, Suécia, Suíça, Tchecoslováquia, Turquia e Ucrânia" (Klink, 2007, p. 25).

${ }^{8}$ Dos países desenvolvidos que não se comprometeram nessa fase foram o Canadá (que se retirou do Protocolo em 2012) e os Estados Unidos
} 
Nesse ínterim, é valido destacar a criação da Agência Internacional de Energias Renováveis (IRENA), em 2010, reunindo 75 países com o objetivo de promover um novo paradigma global de energia, provendo apoio técnico e político, a fim de fomentar a adoção de tecnologias renováveis e transferência tecnológica (IRENA, 2009). Em 2020, mais de 180 países estão engajados e participam da iniciativa.

Até a Conferência Rio+20, inúmeros acontecimentos abalaram os objetivos definidos em Johanesburgo, dentre eles a crise financeira internacional, em 2008, a queda dos preços de combustíveis fósseis (xisto e petróleo) entre 2008 e 2010 e a crise da zona do Euro, em 2010/2011. Diante dos temores de que os países retrocedessem nos esforços de negociações visando ampliar a proteção ambiental, a ONU promoveu, em 2010, uma Conferência em Bali, onde os ministros representantes dos países membros se reuniram e assinaram uma declaração com importantes sinalizações sobre os caminhos da Conferência Rio +20 , a realizar-se dois anos mais tarde (UNEP, 2010). Nesta declaração, difundia-se a ideia de economia verde, termo que adquiriu relevância no contexto de crise e que nortearia orientações políticas. Neste sentido, a expressão não era apresentada como uma alternativa ao desenvolvimento sustentável, que prevaleceu nas declarações da Agenda 21, mas como um dos instrumentos através dos quais o desenvolvimento sustentável seria alcançado. Logo, o discurso vislumbrava alternativas para promoção do bem-estar e da igualdade social, concomitante à redução dos riscos ambientais.
Na ocasião, lançou-se o Global Green New Deal, onde se recomendava que houvesse um estímulo fiscal da ordem de $1 \%$ do PIB mundial (em torno de US\$750 bilhões) a ser investido em tecnologias verdes (UNEP, 2009). Até a Conferência Rio +20 , foram intensificados os esforços no sentido de monitorar metas já estabelecidas, através da publicação da quinta edição do Global Environment Outlook (GEO-5). O documento final da Rio+20, denominado The Future We Want (FWW) (ONU, 2012), propôs a criação de um guia para a implementação de políticas de promoção de crescimento econômico verde, além do estabelecimento de um compromisso, visando ao fim dos subsídios fósseis.

Ainda 2012, ao longo da Rio+20, divulgou-se de maneira consistente a iniciativa Energia Sustentável para Todos (SE4ALL, em inglês) que constituiu um canal para disseminação de ideias e mecanismos de fomento de tecnologias renováveis em todos os setores da sociedade, com metas para 2030 de a) assegurar o acesso universal aos modernos serviços de energia; b) dobrar a taxa global de melhoria da eficiência energética e c) duplicar a quota das energias renováveis na matriz energética global (UNDP, 2011).

Dois órgãos no âmbito da ONU têm especial atuação em torno do tema energia: UNEP, mencionado anteriormente, e o Programa das Nações Unidas para o Desenvolvimento (UNDP em inglês). O UNEP tornou-se o ponto focal da gestão da UNFCCC, das conferências intergovernamentais do meio ambiente e do amparo organizacional ao IPCC. Entre suas prioridades iniciais estavam, 
quando foi criado, em 1972, a oferta de água limpa, a despoluição de oceanos e os assentamentos urbanos (Johnson, 2012). O tema energia apareceu nas primeiras reuniões do órgão como secundário, visando atender à crescente demanda, e não a um objetivo explícito de combater os efeitos das mudanças climáticas, sabendo-se que, à época, esse não era um tema com força técnico-política. Neste bojo, a organização amparou a criação do Intergovernmental Pannel of Climate Change (IPCC), em 1988. Em 1997, com a primeira publicação sobre de alcance global, o Global Environment Outlook (GEO-1), o tema da energia tornou-se uma das três prioridades da organização.

O UNDP, outro órgão relevante para a temática energética, foi estabelecido em 1965 no âmbito do sistema ONU. A promoção de energia renovável pelo programa é feita através de publicações sobre políticas, de financiamento de projetos e capacitação. O órgão também é sócio sênior da iniciativa SE4ALL e promotor dos objetivos do desenvolvimento sustentável (ODS).

Os dezessete ODS foram lançados em setembro de 2015, no contexto da Agenda 2030 pela ONU sob o slogan Transformando Nosso Mundo, estabelecendo ao menos três objetivos diretamente conectados à questão da transição energética e da cooperação multilateral. O ODS7 referente à garantia de acesso à energia barata, confiável, sustentável e renovável para todos, o ODS13 sobre a urgência da adoção de medidas para o combate às mudanças climáticas e seus impactos e o ODS17 promovendo o fortalecimento de meios de implementação da cooperação internacional (UNDP, 2020).

No âmbito das COPs, no mesmo ano de lançamento da Agenda 2030, os países firmaram, em 2015, na COP21, o Acordo de Paris, um instrumento separado sob a UNFCCC, e não uma emenda ao Protocolo de Kyoto. Em vigor desde 2016, o Acordo estabeleceu metas de redução da emissão de GEE a partir de contribuições voluntárias dos países de modo que os governos se envolveram na construção de seus próprios compromissos, a partir do cenário social e econômico local, com Contribuições Nacionalmente Determinadas (NDC, em inglês) (Figueres, 2020).

Em junho de 2017, quando o presidente Donald Trump anunciou que os EUA estariam fora do Acordo de Paris (2015), prefeitos, governadores, universidades e empresas privadas declararam que iriam manter o apoio à iniciativa. Refletindo o movimento da governança policêntrica, esse movimento se materializou em diversas iniciativas tais como a "U.S. Alliance on Climate Change", o "We are still in", entre outras. Na Cúpula de Ação Climática da ONU, de 2019, como destaques o setor privado foi convidado a apresentar metas concretas com as quais poderia se comprometer e os governos locais também puderam se pronunciar (WMO, 2020).

Diante dessa evolução, a ideia de transição energética, no âmbito dos esforços de cooperação multilateral, tornou-se próxima do modelo vislumbrado na perspectiva de governança policêntrica (Ostrom, 2010; 2016), conforme exposto na seção 2. As iniciativas intergovernamentais e não governamentais, envolvendo redes público-privadas, em diversos níveis de governança evoluíram no sentido de pactuar as relações de interdependência, inserindo também o papel do setor privado e dos movimentos sociais no sentido da cooperação (Figueres, 2020), com múltiplos canais de desdobramentos para direcionar a transição energética dos países, como se discutirá a seguir, observando o caso do Brasil. 


\section{Dos elos do internacional e do doméstico: os percalços e ajustes da cooperação multilateral climática e os desdobramentos para as políticas públicas para o setor energético no Brasil}

A partir da exposição histórico-institucional sobre a gênese do RIMC e a complexificação das estruturas de governança, cabe se questionar como o cenário internacional influencia a transição energética em um país? Do ponto de vista empírico, a evolução institucional internacional proporcionou a construção de múltiplos fóruns de cooperação entre os países, com a reunião de representantes de governos e de atores não governamentais, seja dos movimentos da sociedade civil e do setor privado na discussão sobre mudanças climáticas, em múltiplas esferas de poder, debatendo o papel do setor energético e das fontes renováveis como importantes responsáveis nas emissões dos GEE.

Observando o caso específico do Brasil, Dutra (2007) sugere que o interesse em fontes alternativas para geração de energia elétrica se iniciou nos primórdios da década de noventa, especificamente após a Eco92. O evento resultou na implementação de alguns projetos piloto em energia fotovoltaica e energia eólica, a partir de parcerias com os Estados Unidos, a Alemanha e Dinamarca. Desses projetos, destaca-se a implantação de um aerogerador em Fernando de Noronha, a partir de financiamento dinamarquês, em 1992.

Além do prestígio em sediar eventos, fato apontado como fator importante para a reformulação da política energética brasileira (Salino, 2011), os diversos instrumentos negociados ao longo dos anos 1990, como o Protocolo de Kyoto, implicaram transbordamentos para o redirecionamento do planejamento energético do país favorável para a promoção de fontes renováveis de energia (MME, 2009; Salino, 2011). Nesse bojo, o Brasil lançou o Programa de Incentivo às Fontes Alternativas de Energia Elétrica (Proinfa) ${ }^{9}$, em 2002 (Brasil, 2002) com o objetivo de promover fontes alternativas, com projetos que poderiam ser elegíveis à obtenção de créditos de carbono, no contexto do CDM. A Eletrobras foi nomeada como co-participante de projetos de CDM, passando a possuir direitos das receitas provenientes da venda de Certificados de Energia Renovável (CERs) (Salino, 2011) e, de 2003 a 2020, há, no Brasil, 760 registrados nesse mercado, sendo 550 no setor de energia (CDM, 2020). De acordo com Torres et al. (2016), a participação brasileira no segmento de oferta de projetos via CDM ocupa o terceiro lugar mundial em número de projetos (em torno de $4 \%$ ), sendo superado apenas pela China e a Índia com $49,6 \%$ e 20,3\% em número de projetos, respectivamente.

Pela perspectiva da influência no planejamento energético do país, em 2010, o plano decenal de energia de 2020 (MME, 2010; PDE 2020) conferiu destaque às emissões de GEE, haja vista o contexto em que se encontravam as negociações no RIMC e a posição do governo brasileiro que foi evoluindo no sentido de assumir metas de redução de emissões. Conforme a Figura 2, em 1990, o setor de energia ainda não figurava entre os principais responsáveis pelo maior volume de emissões de GEE no país. Porém, ao longo da década de 2000 , as emissões provenientes das atividades relacionadas à geração

${ }^{9} \mathrm{O}$ marco legal do Proinfa está pulverizado entre diversos dispositivos legais, entre leis, decretos, portarias e resoluções, dentre elas destacam-se a Lei ${ }^{\circ}$ 10.438/02 (Brasil, 2002). 
e consumo de energia equipararam-se ao setor de agropecuária, maior emissor em 2014.

Desde 2009, principalmente, com uma redução das emissões brasileiras provenientes da redução do desmatamento, o setor energético passou a figurar em uma posição de atenção em relação às emissões, fato até então minimizado, já que existia, no senso comum, a percepção de o país ter uma matriz energética limpa e que seu maior problema de emissões seria decorrente do mau uso da terra (desmatamento). Sobre essa percepção recorrentemente citada com um atributo positivo da matriz energética brasileira, pondera-se que é preciso observar os dados de maneira cuidadosa. Apesar de a geração de energia eólica no país ter saltado de $1 \mathrm{GW}$ para 15GW em capacidade instalada, entre 2011 e 2019, alcançando $12 \%$ da matriz elétrica ${ }^{10}$ do país (SIGA,
2020), nota-se que a participação da energia solar e eólica na matriz energética, somadas, ainda não passam de 2\% (EPE, 2019).

O compromisso do Brasil nas NDCs era de redução de $37 \%$ das emissões em comparação com 2005 até 2025 de acordo com estudo do Instituto de Pesquisa de Economia Aplicada (IPEA) (Silva et al., 2019). Além disso, mesmo após um contexto de impasses da COP15, em 2009, na ocasião o Brasil anunciou metas voluntárias de redução para 2020. Essa meta foi referendada por meio da Lei ${ }^{\circ}$ 12.187/2009 (Brasil, 2009), que instituiu a Política Nacional sobre Mudança do Clima (PNMC) e foi promulgada pelo Congresso Nacional ainda em dezembro de 2009. Dentre as maneiras de se alcançar tais metas, estabeleceu-se, entre outras iniciativas, reflorestar 12 milhões de hectares de florestas e

\section{" Agropecuária =Energia $\|$ Processos Industriais $\|$ Resíduos =Uso da Terra}

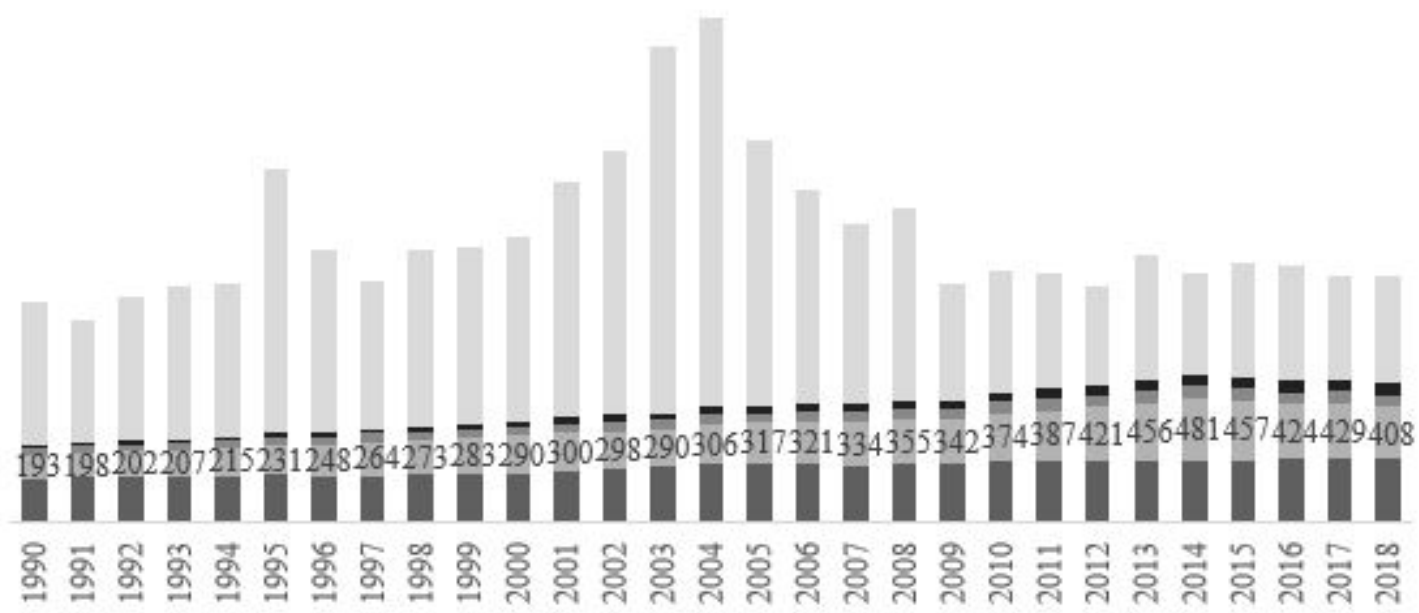

FIGURA 2 - Emissões líquidas de gases estufa no Brasil, por setor, de 1990 a 2018. Destaque para o setor de energia (com os valores descritos) (MtCO2eq).

FONTE: Elaboração própria com base em Sistema de Estimativas de Emissões de Gases de Efeito Estufa, SEEG, acesso em março de (2020).

${ }^{10}$ Enquanto a matriz energética representa o conjunto de fontes de energia total para transporte, eletricidade, aquecimento, a matriz elétrica é formada pelo conjunto de fontes disponíveis apenas para a geração de energia elétrica. 
aumentar a participação de bioenergia sustentável na matriz energética brasileira. Em 2015, a redução já era de 58\%, conforme indicam Silva et al. (2019) e também pode ser observado na Figura 2.

Do ponto de vista dos fundos para sustentar tais iniciativas, a Tabela 3 mostra que o Brasil foi beneficiado em 124 projetos (de um total de 5.058) pelo Global Environmental Facility (GEF), mecanismo de financiamento de projetos relacionados ao setor de energia, mencionado na seção anterior. Isso corresponde a aproximadamente $4 \%$ dos subsídios globais ofertados pelo fundo desde sua criação. Na Tabela 2, observando especificamente os projetos apoiados no Brasil, aproximadamente $25 \%$ estão relacionados à temática das mudanças climáticas.

A partir de 2019, porém, com a ascensão de um novo governo no Brasil, alguns avanços na temática do clima do ponto de vista da cooperação internacional, do marco-regulatório (Freitas, 2020) e da implementação de políticas (Pereira et al., 2020) parecem estar ameaçados, abrindo uma janela de oportunidade para emergência de novos atores destacando-se no contexto da governança policêntrica, especialmente no que tange aos aspectos levantados por Dorsch \& Flachsland (2017).

Do ponto de vista da cooperação internacional, o Brasil perdeu reputação e confiança com sinalizações ambíguas na temática ambiental, seja na gestão das queimadas na Amazônica, bem como no acesso aos recursos do Fundo Amazônia (Gortázar, 2019), os compromissos internacionais com suas metas climáticas de mitigação, as quais tornaram-se condições para concretização de acordo comercial em negociação com a União Europeia (Oliveira et al., 2019).

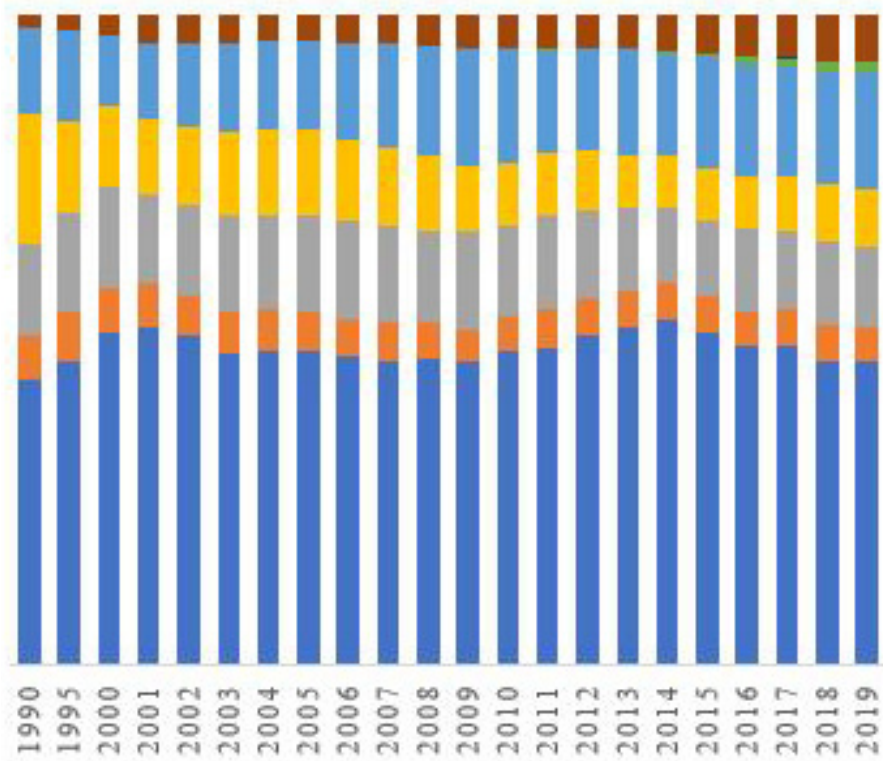

- OUTRAS

- SOLAR

•É́LICA

- PRODUTOS DA CANA

=LENHA E CARVÃO VEGETAL

- HIDRÁULICA E ELETRICIDADE

- CARVÃO MINERAL E DERIVADOS

- PETRÓlEo, GÁs NATURAL E DERIVADOS

FIGURA 3 - Evolução Matriz energética 1990-2020 Brasileira e Matriz Elétrica FONTE: Elaboração própria, a partir de EPE (2019). 
TABELA 4 - Projetos relacionados à energia do GEF para o Brasil, valores em dólares.

\begin{tabular}{lcccc}
\hline \multicolumn{1}{c}{ Setor } & Número de Projetos & Subsídios & Co-financiamento & $6.093 .601 .881,00$ \\
\hline Biodiversidade & 55 & $42.040 .082,00$ & $175.300 .000,00$ \\
Resíduos & 4 & $25.910 .000,00$ & $3.775 .057 .877,00$ \\
Mudanças climáticas & 33 & $631.757 .291,00$ & $1.337 .255 .594,00$ \\
Uso da Terra e outros & 32 & $148.340 .450,00$ & $11.381 .215 .352,00$ \\
Total & 124 & $1.548 .047 .823,00$ & \\
\hline
\end{tabular}

FONTE: Elaboração própria a partir de GEF (2020).

No que tange ao aspecto de reconhecimento das condições específicas do local, fortaleceu-se, no Brasil, um movimento de subnacionalização da questão climática. De maneira similar a iniciativas norte-americanas, gestores brasileiros comprometidos com a causa climática materializaram a iniciativa Governadores pelo Clima ${ }^{11}$, idealizada pelo Centro Brasil no Clima (CBC). Nesse arcabouço, em mais um episódio de enfraquecimento de confiança, o Brasil foi vetado de discursar na Cúpula de Ação Climática das Nações Unidas, em 2019, tendo sido uma das referências na construção do Acordo de Paris (2015), com a formulação das contribuições nacionalmente determinadas com ampla participação da sociedade civil, em 2019. Em contraposição, para a mesma ocasião o governador de Pernambuco, Paulo Câmara, foi convidado a discursar por conta de seu trabalho na arena ambiental (Revista Fórum, 2019).

Em 2020, enquanto entidades da sociedade civil afirmam que o país está longe de cumprir suas metas (Observatório do Clima, 2019), Silva et al. (2019) declaram que o país está nos trilhos de cumprimento de suas metas, considerando de um espectro mais amplo o cumprimento do ODS13, sobre Tomar Medidas Urgentes para Combater a Mudança do Clima e seus Impactos.

Em suma, apesar de significativos avanços da política climática brasileira até 2017, Basso (2019) argumenta que a descarbonização profunda no país tem sido desafiada por disputas políticas que têm levado o país a retroceder nos avanços nessa área, dentre os quais se destacam o avanço do desmatamento e, principalmente, da degradação da mata por meio de incêndios florestais (Assis et al., 2020; INPE, 2020). Nesse tema, Pereira et al. (2020) sugerem que um ciclo de retroalimentação que conecta políticos, agricultores e a redução da proteção ambiental. De outro lado, ponderam-se, ainda, os inúmeros desafios socioambientais relacionados à adoção de energias renováveis tais como a solar (Bursztyn, 2020) e a eólica (Galvão et al., 2020) que começam a ser avaliados após muitos projetos passarem a ser implantados, bem como os efeitos controversos do etanol (Galdos et al., 2013).

\footnotetext{
${ }^{11}$ Conforme Agência Brasília (2019), na ocasião, representantes de Amapá, Amazonas, Distrito Federal, Espírito Santo, Mato Grosso do Sul, Minas Gerais, Paraná, Pernambuco, Rio de Janeiro, Rio Grande do Norte, Rio Grande do Sul e São Paulo declararam estar de acordo com as metas estabelecidas pelo Brasil para enfrentamento das mudanças climáticas.
} 


\section{Considerações finais}

O tema das mudanças climáticas ganhou relevância significativa, na agenda internacional, desde os primeiros eventos e publicações dos anos 1960 e 1970 . Um movimento que parece ter se iniciado a partir do movimento ambientalista moderno, difundiu-se para as arenas de discussão através de importantes publicações e conferências internacionais, com ampla participação e debates entre países. A partir dos anos 1990, a temática foi crescentemente se espraiando para setores para além da academia e dos movimentos sociais, passando também a permear o setor privado e iniciativas de articulação de redes público-privadas.

Nos anos 2000, a abordagem dos regimes internacionais, muito forte entre os estudos ambientais ao longo dos anos 1990, já não contemplava as múltiplas esferas de negociação e adoção de medidas que, observando especificamente o setor da energia, levassem os países à transição energética. Em um novo aparato teórico-conceitual, houve uma proliferação de estudos relacionados à temática do meio ambiente no bojo da governança climática e, alguns anos depois, amparados no guarda-chuva da governança policêntrica. Nota-se, portanto, que observar os canais de transmissão do internacional para o nacional, passa por constatar o aumento da velocidade da disseminação de informações, estudos, projetos e normas amparados pelos programas, agências, fundos e conferências do RIMC, mas também investigar outros múltiplos canais de transmissão de ideias e iniciativas, a exemplo de ações do setor privado e da sociedade civil.

A adoção das políticas de incentivo à energia renovável no Brasil não foi resultado apenas de decisões amparadas por questões de segurança do abastecimento e interrupções do fornecimento, com a possibilidade de esgotamento das fontes tradicionais - como até meados dos anos 1990 - nem da simples operação da demanda e oferta de mercado, mas envolveu diversos fatores que impactaram essa conjuntura, tais como: o contexto do fim da Guerra Fria, o fortalecimento do movimento ambientalista nos foros internacionais, a atuação de organizações intergovernamentais (multilaterais) e também do setor privado que tem, crescentemente, ganhado importância na questão climática, principalmente com a consolidação das ideias de governança híbrida (público-privada), amplamente difundas através dos ODS e costuradas no acordo de Paris (2015). Nesse sentido, a ação de atores, internacionais e domésticos, públicos e privados, tem se mostrado fundamental para engendrar um processo que leve o setor de energias renováveis a alcançar uma engrenagem própria, assim como acredita ter acontecido nos Estados Unidos, o ex-presidente do país, Barack Obama (Obama, 2017).

Portanto, cabe ressaltar que a complementaridade entre a produção energética, a partir de fontes renováveis, como forma de garantia da segurança energética, e as questões ambientais atreladas à temática, são importantes faces na análise da formação de uma agenda internacional sobre mudanças climáticas, e das diretrizes que são estabelecidas referente à diversificação das fontes para produção de energia. De um lado, nota-se considerável avanço, principalmente com a promoção de fontes renováveis para além da hidrelétrica. Por outro lado, novos desafios se colocam, especialmente no que tange aos impactos negativos socioambientais locais que resultam da exploração e comercialização desses recursos e de rupturas tecnológicas importantes que 
podem transbordar para a dimensão político-regulatória. Essa é uma agenda complexa que não se esgota e nem se restringe a uma análise circunscrita a um único ator ou a uma única dimensão decisória que, por isso, pode muito avançar dentro da abordagem da governança policêntrica.

\section{Referências}

Agência Brasília. Formação do Conselho dos Governadores do Clima avança em Brasília, 2019. Disponível em: <https://www.agenciabrasilia.df.gov.br/2019/06/25/ formacao-do-conselho-dos-governadores-do-clima-avanca-em-brasilia/>. Acesso em: jun. 2020.

Aguiar, M. H. P.; Mattos, B. R. B.; Cardoso, N. T. O discurso ambiental brasileiro e a transformação do conceito de soberania: uma análise de Estocolmo à Rio+ 20. Estudos Internacionais, 3(1), 141-164, 2015.

Almeida, M.; Paiva, I.; Muniz, A. W. O. Papel do Regime Internacional de Mudanças Climáticas na Promoção de Políticas Domésticas de Mitigação no Setor de Energia. RP3-Revista de Pesquisa em Políticas Públicas, 1(1),781012017.

Alves, E. E. C.; Steiner, A.; de Almeida Medeiros, M.; da Silva, M. E. A. From a breeze to the four winds: A panel analysis of the international diffusion of renewable energy incentive policies (2005-2015). Energy Policy, 125, 317329, 2019.

Assis, T. O.; Aguiar, A. P. D.; von Randow, C.; de Paula Gomes, D. M.; Kury, J. N.; Ometto, J.; Nobre, C. A. CO 2 emissions from forest degradation in Brazilian Amazonia. Environmental Research Letters, (15), 1-11, 2020.

Basso, L. Brazilian energy-related climate (in)action and the challenge of deep decarbonization. Revista Brasileira de Política Internacional, 62(2), 1-21, 2019. doi: 10.1590/00347329201900202

Bauer, S. The Desertification Secretariat: A Castle Made of Sand. In: Biermann, F.; Siebenhuner, B. Managers of global change: The influence of international environmental bureaucracies. Cambridge: MIT, 2009. p. 293-307.

Baylis, J. The globalization of world politics: an introduction to international relations. Oxford: Oxford University Press, 2020.

Biermann, F. Global Governance and the Environment: In: Betsill, M.; Hochstetler, K; Stevis, D. (Eds.). Advances in International Environmental Politics. New York: Palgrave Macmillan, 2006. p. 237-261.

Brasil. Lei n ${ }^{\circ} 10.438$ de 26 de abril de 2002 cria o Programa de Incentivo às Fontes Alternativas de Energia Elétrica (Proinfa). Brasília: DOU, 2002.

Brasil. Lei $\mathrm{n}^{\circ} 12.187$ de 29 de dezembro de 2009, institui a Política Nacional sobre Mudança do Clima, Brasília: DOU, 2009.

Brundtland, G. H. Our Common Future. New York: United Nations, 1987.

Bursztyn, M. Energia solar e desenvolvimento sustentável no Semiárido: o desafio da integração de políticas públicas. Estudos Avançados, 34(98), 167-186, 2020.

CAIT - Climate Data Explorer. World Resources Institute. Disponível em: $<$ http://cait.wri.org/>. Acesso em: jun. 2020.

Carson, R. Silent Spring. Greenwich, Connecticut: Mariner Books, 1962.

Camillo, E. V. As políticas de inovação da indústria de energia eólica: uma análise do caso brasileiro com base no estudo de experiências internacionais. Campinas, Tese (Doutorado em Geociências) - Unicamp, 2013.

CDM - Clean Development Mechanism. Project Research. Disponível em: $<$ https://cdm.unfccc.int/Projects/projsearch. html>. Acesso em: jun. 2020.

Chasek, P. S. Global environmental politics. London: Routledge, 2018.

Clapp, J.; Helleiner, E. International political economy and the environment: back to the basics? International Affairs, 88(3), 485-501, 2012.

Cole, D. H. Advantages of a polycentric approach to climate change policy. Nature Climate Change, 5(2), 114-118, 2015.

Dauvergne, P. Handbook of global environmental politics. 
Canadá: University of British Columbia, 2005.

de Souza, A.; Souza, J.; Kruger, E. Os programas brasileiros em eficiência energética como agentes de reposicionamento do setor elétrico. Revista Tecnologia e Sociedade, 7(12), $1-7,2011$.

Dorsch, M. J.; Flachsland, C. A polycentric approach to global climate governance. Global Environmental Politics, 17(2), 45-64, 2017.

Dutra, R. M. Propostas de políticas especificas para energia eólica no Brasil após a primeira fase do PROINFA. Rio de Janeiro, Tese (Doutorado em Ciências em Planejamento Energético) - UFRJ, 2007.

EPE - Empresa de Pesquisa Energética. Balanço Energético Nacional 2019: ano base 2018. Rio de Janeiro: EPE, 2019. Disponível em: <https://www.epe.gov.br/pt/publicacoes-dados-abertos/publicacoes/balanco-energetico-nacional-2019>. Acesso em: mai. 2020.

Falkner, R. Private Environmental Governance and International Relations: exploring the Links. Global Environmental Politics, 3(2), 72-87, 2003.

Falkner, R. (Ed.). The handbook of global climate and environment policy. New Jersey: John Wiley \& Sons, 2013.

Faria, V. D. de. Política externa e participação social: trajetória e perspectivas. Brasília: Funag, 2017.

Figueres, C. Paris taught me how to do what is necessary to combat climate change. Nature, 577, 470-471, 2020. doi: 10.1038/d41586-020-00112-6

Revista Fórum. ONU rejeita Bolsonaro e convida governador do Nordeste para discursar na Cúpula do Clima, 2019. Disponível em: $<$ https://revistaforum.com.br/politica/onu-rejeita-bolsonaro-e-convida-governador-do-nordeste-para-discursar-na-cupula-do-clima/>. Acesso em: jun. 2020.

Freitas, H. Barroso convoca audiência pública sobre situação do meio ambiente no Brasil. Jota, 2020. Disponível em: <https://www.jota.info/paywall?redirect_to=//www. jota.info/stf/do-supremo/meio-ambiente-audiencia-publica-29062020>. Acesso em jun. 2020.

Galdos, M.; Cavalett, O.; Seabra, J. E.; Nogueira, L. A. H.; Bonomi, A. Trends in global warming and human health impacts related to Brazilian sugarcane ethanol production considering black carbon emissions. Applied Energy, 104, 576-582, 2013.

Galvão, M. L. D. M.; dos Santos, M. A.; da Silva, N. F.; da Silva, V. P. Connections Between Wind Energy, Poverty and Social Sustainability in Brazil's Semiarid. Sustainability (2071-1050), 12(3), 1-25, 2020.

GEF - Global Environmental Facility. Projects. Disponível em: <https://www.thegef.org/projects $>$. Acesso em: jun. 2020 .

Gilligan, M. J. Is enforcement necessary for effectiveness? A model of the international criminal regime. International Organization, 60(4), 935-967, 2006.

Goldsmith E.; Allen, R.; Allaby, M. A blueprint for survival. Boston: Houghton Mifflin, 1972.

Gortázar, N. G. El País Brasil. O que há por trás das chamas na Amazônia, 2019. Disponível em: <https://brasil.elpais. com/brasil/2019/10/22/eps/1571696000_250069.html>. Acesso em: jun. 2020

Haas, P. M. Science and international environmental governance. In: Dauvergne, P. (Ed.) Handbook of Global Environmental Politics. New York: Edward Elgar Publishing Limited, 2005. p. 383-401.

Hardin, G. The tragedy of the commons. Science, 162(3859), 1243-1248, 1968.

Harjanne, A.; Korhonen, J. M. Abandoning the concept of renewable energy. Energy Policy, 127, 330-340, 2019.

INPE - Instituto Nacional de Pesquisas Espaciais. A taxa consolidada de desmatamento por corte raso para os nove estados da Amazônia Legal (AC, AM, AP, MA, MT, PA, RO, RR e TO) em 2019 é de $10.129 \mathrm{~km}^{2}, 2020$. Disponível em: <http://www. inpe.br/noticias/noticia.php?Cod_Noticia $=5465>$. Acesso em: jun. 2020.

IPCC - Intergovernmental Panel of Climate Change. Special Report on Renewable Energy Sources and Climate Change Mitigation. Cambridge: Cambridge University Press, 2011. Disponível em: $<$ http://srren.ipccwg3.de/report/IPCC_SRREN_Full_Report>. Acesso em: out. 2016.

IPCC - Intergovernmental Panel of Climate Change. 
Climate Change 2014: Synthesis Report. Contribution of Working Groups I, II and III to the Fifth Assessment Report of the Intergovernmental Panel on Climate Change. Core Writing Team, R.K. Pachauri and L.A. Meyer (Eds.). Geneva, Switzerland, 2014.

IRENA - International Renewable Energy Agency. Statute of IRENA signed in Bonn. Conference on the establishment of the international renewable energy agency. Bonn: World Conference Center, 2009.

Ivanova, M. Designing the United Nations Environment Programme: a story of compromise and confrontation. International Environmental Agreements: Politics, Law and Economics, 7(4), 337-361, 2007.

Johnson, S. P. UNEP: the first 40 years: a narrative. New York: United Nations Development Programme, 2012.

Jordan, A.; Hiutema, D. Policy innovation in a changing climate: sources, patterns and effects. Global Environmental Change, 29, 387-394, 2014.

Jordan, A. J.; Huitema, D.; Hildén, M.; Van Asselt, H. Emergence of polycentric climate governance and its future prospects. Nature Climate Change, 5(11), 977-982, 2015.

Keck, M. E.; Sikkink, K. Activists beyond Borders: Advocacy Networks in International Politics. Ithaca: Cornell University Press, 1998.

Keohane, R. O. After Hegemony: cooperation and discord in the world economy. Princeton, NJ: Princeton University Press, 1984.

Klink, C. Quanto mais quente melhor: Desafiando a sociedade civil a entender as mudanças climáticas. São Paulo: Peirópolis, 2007.

Krasner, S. (Ed.). International Regimes. Ithaca: Cornell University Press, 1983.

Lakoff, G. The all new don't think of an elephant!: Know your values and frame the debate. New York: Chelsea Green Publishing, 2014.

Liu, L. A new perspective on combating global climate change. Transnational Corporations Review, 2(1), 78-81, 2010.

McGinnis, M. D. An introduction to IAD and the language of the Oström workshop: a simple guide to a complex framework. Policy Studies Journal, 39(1), 169-183, 2011.

Meadows, D.; Meadows, D.; Randers, J.; Behrens III, W.W. The limits to growth. New York: Chelsea Green Publishing Company, 1972.

Mitchell, R. B.; Mitchell, R. B.; Choucri, N.; Gasser, L. Intentional oil pollution at sea: environmental policy and treaty compliance. Cambridge: MIT Press, 1994.

Mitchell, C.; Sawin, J. L.; Pokharel, G. R.; Kammen, D.; Wang, Z. Policy, Financing and Implementation. In: Edenhofer, O., Pichs Madruga, R.; Sokona, Y.; Seyboth, K. (Eds.). IPCC Special Report on Renewable Energy Sources and Climate Change Mitigation. Cambridge; New York: Cambridge University Press, 2011. p. 865-950.

MME - Ministério de Minas e Energia. Relatório do Grupo de Trabalho em Sistemas Fotovoltaicos - GT-GDSF. Brasília: MME, 2009.

MME - Ministério de Minas e Energia. Plano Decenal de Energia 2020. Plano decenal de expansão de energia 2020 (PDE 2020). Brasília-DF: MME; EPE, 2010.

Obama, B. The irreversible momentum of clean energy. Science, 355(6321), 126-129, 2017.

Observatório do Clima. Brasil não deve cumprir nem meta menos ambiciosa no clima, 2019. Disponível em: <http:// www.observatoriodoclima.eco.br/brasil-nao-deve-cumprir-nem-meta-menos-ambiciosa-no-clima/>. Acesso em: jun. 2020.

Oliveira, J.; Alessi, G; Bedinelli, T. El País Brasil. Política ambiental de Bolsonaro ameaça acordo com UE e alarma até agronegócio exportador, 2019. Disponível em: <https://brasil.elpais.com/brasil/2019/08/16/politica/1565909766_177145.html z, acesso em jun. 2020.

Olson, M. The theory of collective action: public goods and the theory of groups. Cambridge: Harvard University Press, 1965.

ONU - Organização das Nações Unidas. The Future we want, 2012. Disponível em: <https://www.un.org/ga/search/ view_doc.asp?symbol=A/RES/66/288\&Lang=E $\geq$. Acesso em: jun. 2020.

ONU - Organização das Nações Unidas. Saiba o que foi 
prometido durante a histórica Cúpula de Ação Climática da $O N U$. Nações Unidas Brasil. Disponível em: https://nacoesunidas.org/saiba-o-que-foi-prometido-durante-a-historica-cupula-de-acao-climatica-da-onu/. Acesso em: jun. 2020

Ostrom, E. Governing the commons: The evolution of institutions for collective action. Cambridge: Cambridge University Press, 1990.

Ostrom, E. A General Framework for Analyzing Sustainability of Social-Ecological Systems. Science, 325(5939), 419-22, 2009.

Ostrom, E. Polycentric systems for coping with collective action and global environmental change. Global environmental change, 20(4), 550-557, 2010.

Ostrom, E. Nested Externalities and Polycen '1tric Institutions: Must We Wait for Global Solutions to Climate Change Before Taking Actions at Other Scales? In: Chichilnisky G.; Rezai A. (Eds.). The Economics of the Global Environment. Studies in Economic Theory. New York: Springer, v. 29, 2016. p. 353-369.

Pereira, E. J. de A. L.; de Santana Ribeiro, L. C.; da Silva Freitas, L. F.; de Barros Pereira, H. B. Brazilian policy and agribusiness damage the Amazon rainforest. Land Use Policy, 92(104491), 1-6, 2020.

Podcameni, M. G. Sistemas de inovação e energia eólica: a experiência brasileira. Rio de Janeiro, Tese (Doutorado em Economia) - UFRJ, 2014.

Ribeiro, Z. B. Parâmetros para análise de projetos de eficiência energética em eletricidade. São Paulo: USP, 2005.

Rowlands, I. H. Global climate change and renewable energy: exploring the links. In: Rowlands, I. H. Switching to Renewable Power. London: Routledge, 2012. p. 79-99.

Ruggie, J. G. International regimes, transactions, and change: embedded liberalism in the postwar economic order. International Organization, 36(2), 379-415, 1982.

Salino, P. J. Energia eólica no Brasil: uma comparação do PROINFA e dos novos leilões. Rio de Janeiro, Projeto de Graduação (Graduação em Politécnica) - Escola Politécnica, UFRJ, 2011.

Salomão, L. A.; Silva, J. M. Energia. In: Moscardo, J.;
Cardim, C. H. (Orgs.). I Conferência Nacional de Política Externa e Política Internacional: O Brasil no mundo que vem aí. Rio de Janeiro: Fundação Alexandre de Gusmão (FUNAG), 2007.

Sato, E. A agenda internacional depois da Guerra Fria: novos temas e novas percepções. Revista Brasileira de Politica Internacional, 43(1), 138-169, 2000.

Siga - Sistema de Informações de Geração da ANEEL. Disponível em: <https://www.aneel.gov.br/siga> Acesso em: jun. 2020

Silva, E. R da. A.; Peliano, A. M.; Chaves, J. ODS 13: Tomar Medidas Urgentes para Combater a Mudança do Clima e seus Impactos. Brasília: IPEA, 2019. Disponível em: <https://www.ipea.gov.br/portal/index.php?option=com_content\&view $=$ article $\& i d=35102 \&$ Itemid $=444>$. Acesso jun. 2020

Siqueira, C. D. Regime internacional de mudanças climáticas e segurança energética. Mediações-Revista de Ciências Sociais, 16(2), 210-227, 2011.

Sovacool, B. K.; Roman V. S; Jones, B.R. Energy security, equality and justice. London: Routledge, 2013.

Teixeira de Barros, A. Brazil's Discourse on the Environment in the International Arena, 1972-1992. Contexto Internacional, 39(2), 421-442, 2017.

Torres, C.; Fermam, R.; Sbragia, I. Projetos de MDL no Brasil: oportunidade de mercado para empresas e para novas entidades operacionais designadas. Ambiente \& Sociedade, 19(3), 199-212, 2016.

UNDP - United Nations Development Programme. UNDP in Action. Annual Report 2010/2011. New York: United Nations Development Programme, 2011.

UNDP - United Nations Development Programme. 17 Objetivos para transformar nosso mundo, 2020. Disponível em: $<$ https://nacoesunidas.org/pos2015/>. Acesso em jun. 2020.

UNEP - United Nations Environment Programme. Global Green New Deal (GGND), Policy Brief., 2009.

UNEP - United Nations Environment Programme. Nusa Dua Declaration, UNEP/GCSS.XI/L.6. Bali: UNEP, 2010.

UNFCCC - United Nations Framework Convention on 
Climate Change, 1992. Disponível em: < https://unfccc.int/ files/essential_background/background_publications_htmlpdf/application/pdf/conveng.pdf $>$. Acesso em jun. 2020

Veiga, J. P. C.; Zacareli, M. A. Regimes Internacionais Do intergovernamental público às arenas transnacionais público-privadas. História e Cultura, 4, 302-318, 2015.

Viola, E. O Regime Internacional de Mudança Climática e o Brasil. Revista Brasileira de Ciência Social, 17(50), 25-46, 2002.

Viola, E; Gonçalves, V.K. Brazil ups and downs in global environmental governance in the 21 st century. Revista Brasileira de Política Internacional 62(2), 1-10, 2019. doi: doi.org/10.1590/0034-7329201900210_
Yergin, D. The prize: the epic quest for oil, money and power. New York: Simon \& Schuster, 2008.

Young, O. R. International Cooperation: Building Regimes for Natural Resources and the Environment. Ithaca, NY: Cornell University Press, 1989.

Young, O. R. (Ed.). Global Governance. Drawing Insights from the Environmental Experience. Cambridge, Mass.: MIT Press, 1997.

Young, O. R. (Ed.). The effectiveness of international environmental regimes: causal connections and behavioral mechanisms. Cambridge: MIT Press, 1999.

WMO - World Meteorological Organization. WMO Statement on the State of the Global Climate in 2019, 2020. Disponível em: $<$ https://library.wmo.int/doc_num.php?explnum_id=10211>. Acesso em: jun. 2020. 